\title{
The immune-opioid axis in prediabetes: predicting prediabetes with insulin resistance by plasma interleukin-10 and endomorphin-2 to kappa-opioid receptors ratio
}

Shatha Rouf Moustafa*

\begin{abstract}
Background: Prediabetes is characterized by a hemoglobin A1c of $5.7-6.4 \%$ and fasting blood glucose of 100-125 mg/dl. A high percentage of prediabetes subjects develop type 2 diabetes mellitus in the next years. The effects of opioid peptides and their receptors, in addition to immunological cytokines, on prediabetes are not well understood. Therefore, molecular, physiological, and clinical studies are required to link the opioid system, immune system, and insulin resistance (IR) in prediabetes. We hypothesize that opioid peptides (endomorphin-2 (EM2), and $\beta$-endorphin ( $\beta E P)$ ), and their receptors ( $\mu$-opioid receptors (MOR) and $k$-opioid receptors (KOR)), in addition to the inflammatory cytokines (IL-6) and anti-inflammatory cytokine (IL-10), affect IR parameters in patients with prediabetes.

Methods: Sixty prediabetes patients with IR (prediabetes+IR) and sixty prediabetes patients without IR (prediabetesIR), in addition to 58 controls, have participated in the study. IL-6, IL-10, EM2, $\beta E P, M O R$, and KOR were measured by the ELISA technique.

Results: In general, most prediabetes subjects have dyslipidemia. The IL-6, IL-10, $\beta$-endorphin, MOR, and endomorphin-2 were higher in the prediabetes subgroups than the control group. The immune system was activated in the prediabetes in an IR-dependent manner. Prediabetes+IR can be predicted by the increased levels of IL-10, $\beta E P$, and EM2 and by the combination of IL-10 and EM2/KOR with good sensitivity and specificity.

Conclusion: Opioid peptides and their receptors were upregulated in patients with prediabetes, depending on the significance of IR and the immune cytokines. The intercorrelation between the immune system, EOS, and insulin in prediabetes was confirmed.
\end{abstract}

Keywords: Prediabetes, Insulin resistance, Interleukin, Endorphin, Endogenous opioid receptor

\section{Background}

Impaired fasting blood glucose (FBG) or glucose tolerance develops years before evolving into a strong type 2 diabetes mellitus (T2DM), and this disorder is known as prediabetes, a major risk factor for diabetes development

\footnotetext{
*Correspondence: shatha003@yahoo.com
}

Clinical Analysis Department, College of Pharmacy, Hawler Medical University, Roya Towers C21, Erbil, Iraq
[1]. About $34.5 \%$ of American adults over 18 years of age (88 million people) have prediabetes experience prediabetes, a disorder associated with higher hemoglobin A1c (HbA1c) and fasting blood glucose (FBG) levels than average but not significantly elevated to be grouped as diabetes mellitus [2]. Prediabetes is classified as HbA1c level between 5.7 and $6.4 \%$ and FBG between 100 and $125 \mathrm{mg} / \mathrm{dl}$ in the latest US guidelines [3].

c) The Author(s) 2021. This article is licensed under a Creative Commons Attribution 4.0 International License, which permits use, sharing, adaptation, distribution and reproduction in any medium or format, as long as you give appropriate credit to the original author(s) and the source, provide a link to the Creative Commons licence, and indicate if changes were made. The images or other third party material in this article are included in the article's Creative Commons licence, unless indicated otherwise in a credit line to the material. If material is not included in the article's Creative Commons licence and your intended use is not permitted by statutory regulation or exceeds the permitted use, you will need to obtain permission directly from the copyright holder. To view a copy of this licence, visit http://creativeco mmons.org/licenses/by/4.0/. The Creative Commons Public Domain Dedication waiver (http://creativecommons.org/publicdomain/ zero/1.0/) applies to the data made available in this article, unless otherwise stated in a credit line to the data. 
Insulin resistance (IR) means the reduced sensitivity or reactivity of tissues to insulin-mediated biologic activity that leads to high glucose levels and represents the major risk factor of prediabetes and T2DM $[4,5]$. IR, impaired insulin function, and hypersecretion of insulin are the main factors in prediabetes pathophysiology [6]. A large percentage of prediabetes patients showed a rise in IR index, and they labeled as insulin-resistant patients when the value of the homeostasis model assessment of the insulin resistance (HOMA2IR) reaches the cut-off value $(>2.5)[7,8]$. When blood glucose increases, it enters the hemoglobin and raises the HbA1c level that is considered as an indicator for $\beta$-cell function and the IR state [9]. There is evidence that connects insulin with the development of neurons and their normal functions. Insulin signaling is essential for the neurons' survival, learning, and memorization $[10,11]$. Impaired insulin signaling in animal models leads to a collection or assembly of A $\beta$ oligomers [12]. At formation, A $\beta$ oligomers exhaust insulin receptors from the neuronal surface membrane, leading to IR and producing abnormal phosphorylation of the insulin receptor substrate (IRS) [13]. This state reduces the neurons' normal pro-survival signaling and promotes apoptosis to their death [14]. Notably, such structural network anomalies are related to the delay in processing information speed [15]. Elevated IR that occurs during midlife may increase the risk of cognitive impairment later in life, demonstrated by reduced verbal fluency and sluggish basic response time [16].

The relationship between IR parameters and endogenous opioid system (EOS) molecules and receptors that have many brain functions in some insulin-related disorders, including prediabetes, remains to be elucidated. EOS consists of peptides such as $\beta$-endorphin $(\beta E P)$ and endomorphin-2 (EM2) and their receptors, $\mu$-opioid receptors (MOR) and $\mathrm{k}$-opioid receptors (KOR). In addition to producing analgesia, opioids control glucose homeostasis by altering insulins' secretion [17]. There is evidence that stimulation of adrenal gland adrenoceptors can increase the secretion of $\beta$-endorphin, which stimulates peripheral MOR to alter glucose-associated genes, leading to improved peripheral glucose consumption and decreased hepatic gluconeogenesis for the improvement of extreme hyperglycemia [18]. The analysis of EOS peptides and receptors in animals and humans and their potential effect on insulin and glucagon release indicated that opioids might regulate insulin resistance and glucose metabolism [18, 19]. It is found that the MOR pathway is responsible for the improvement of insulin sensitivity [19]. Opioid receptors are found in the pancreas and the alpha and beta-pancreatic cells, thereby influencing endogenous opioid-mediated glucose and insulin homeostasis. Beta-endorphin has a strong relationship with the $\beta$-cell function and is considered an important predictor for differentiating between high and low $\beta$-cell functions [20]. Analysis of the isolated $\beta$-islets suggests that MOR directly mediates islet insulin hypersecretion and manages insulin release to the body compartments [21]. Opioids affect the function of $\beta$-cells in people who use heroin (MOR agonist), leading to increase blood glucose levels [22] and HbA1c [23]. The mechanisms behind these phenomena are increased use of glucose and decreased hepatic gluconeogenesis following improvement of peripheral MOR and heterogeneity of genes in glucose metabolism [18], in addition to the hyperglycemia caused by a chronic opioid receptor activation [24]. MOR mediates the inhibitory effects of EM2, which exercises a reduced role in diabetes. Besides, poor regulation of blood glucose can lead to the attenuated effects of EM2 [31].

The immune system molecules, particularly interleukin (IL)-6 and IL-10, are other important molecules that mediate the inflammatory response and need more study in prediabetes. Interleukin-6 (IL-6) is a pro-inflammatory cytokine that unequivocally motivates IR progression and T2DM pathogenesis via inflammation generation by regulating differentiation, migration, proliferation, and apoptosis of cells [25]. IL- 6 has been examined since it is positively associated with the expression of the insulin-degrading enzyme (IDE), where the deficiency of IDE is related to obesity and T2DM [26]. Some results denote IL-6 's novel role in insulin metabolism, suggesting a mechanistic link between the IL- 6 promotion and the IR promotion [25]. IL-10 is a cytokine with anti-inflammatory properties, modulating inflammatory responses by repressing the generation of pro-inflammatory cytokines [27]. Serum IL-10 has a converse relationship with hyperinsulinemia and IR, as IL-10 decreases with HOMA-IR increased [28].

This study hypothesized that opioid peptides and their receptors combined with the immune cytokines (IL-6 and IL-10) affected the IR parameters in prediabetes patients. The null hypothesis is a lack of intercorrelation between all the three systems and no correlation between prediabetes and these systems. This work's findings may potentiate the pharmacological intervention by targeting IR through the EOS components and immune biomarkers. To examine these hypotheses, we measured serum levels of some opioids proteins and receptors in addition to IL-6 and IL-10 levels in prediabetes patients who have/have not an IR state and compared with the healthy controls. 


\section{Subjects and methods Subjects}

More than 500 subjects, who check FPG routinely in the laboratories, were examined to select our study group with restricted criteria. A total of 120 subjects with prediabetes were chosen to participate in the study. A physician diagnosed these subjects under the American Diabetes Association's criteria (FPG $=5.55-6.94 \mathrm{mM}$, HbA1c $=5.7-6.4 \%)$. The samples were collected from the Rizgari Teaching Hospital and private clinics and laboratories in Erbil City, Kurdistan Region, Iraq, from October 2019 to December 2019. All procedures were conducted following the established ethical standards. All study subjects provided written informed consent before participation in the study. The study was carried out under the international and Iraq ethics and privacy laws and approved by the Ethics Committee of Medical Research at the College of Pharmacy/Hawler Medical University. The reference No. of the ethical approval paper is HMUPH-EC 191223/102. All procedures were performed according to the Helsinki Declaration's ethical standards for experiments involving humans, as revised in 2013.

The subjects with prediabetes were further divided into two subgroups following the results of HOMA2IR. The first group, prediabetes+IR, comprised subjects with a high IR state (HOMA2IR > 2.5). The second group, prediabetes-IR, comprised subjects with a low IR state (HOMA2IR <2.5). This classification occurred deliberately in the same number of subjects in the two groups to remove the number of cases' possible bias. Fifty-eight healthy subjects were selected as the control group. Age ranges and sex ratios were matched in all the study groups. None of these subjects manifested any evident systemic disease or took drugs. Furthermore, in all subjects, the C-reactive protein (CRP) was negative (lower than $6 \mathrm{mg} / \mathrm{l}$ ) to exclude overt inflammation. Tobacco use disorder (TUD) was examined under the DSM-IV-TR criteria. Body mass index (BMI) was calculated using the formula: body weight $(\mathrm{kg}) /$ squared height $\left(\mathrm{m}^{2}\right)$. Subjects performing more than $30 \mathrm{~min}$ of moderate activity 2-3 times/week and never orless than one time per week were considered as a person with physical activity [3].

\section{Exclusion criteria}

The present study excluded patients who met the following criteria: serum TG $>5.32 \mathrm{mM}$ patients to satisfy the Friedewald's formula, FPG $>25 \mathrm{mM}$, and fasting insulin $>400$ pM to satisfy the HOMA calculator software requirements. Any patient with apparent diabetes mellitus, heart disease, hypertension, and those taking lipidlowering drugs (e.g., simvastatin or atorvastatin) and metformin was excluded. We also excluded any subject with a urinary albumin/creatinine of more than $30 \mathrm{mg} / \mathrm{g}$ to exclude microalbuminuria, which indicated damage to the microvessels.

\section{Measurements}

After at least $12 \mathrm{~h}$ of fasting, blood samples were collected in the morning and transferred into a plain tube and EDTA tubes. After clotting, sera samples were separated and divided into three aliquots and stored in a refrigerator before use. The serum glucose, total cholesterol, and TG were measured using commercially available kits supplied by Spinreact ${ }^{\circledR}$, Spain. The absorbances were measured by using a visible spectrophotometer (model 722,

Shanghai Lianhua Industrial Co. Ltd., China). Serum HDLc was measured after precipitation of other lipoproteins using a reagent containing sodium phosphotungstate and magnesium chloride. The cholesterol content of the supernatant was measured using a cholesterol kit. VLDLc was determined using Friedewald's equation (LDLc $=$ Tc - HDLc - VLDLc), based on TG/2.19 and LDLc. The percentage of HbA1c in the whole blood (EDTA tube aliquot) and the urinary albumin/creatinine ratio were measured using the immunofluorescence analyzer (Finecare ${ }^{\mathrm{TM}}$ II FIA Meter, Guangzhou Wondfo Biotech Co., Ltd, China). The normal range of the HbA1c kit was $4-6 \%$, and the microalbumin ratio was less than $30 \mathrm{mg} / \mathrm{g}$. The IR parameters were calculated from the fasting glucose and insulin concentrations using the HOMA calculator program (http://www.dtu.ox.ac.uk/ HOMA-calculator/download.php). The insulin resistance function (HOMA2IR), insulin sensitivity (HOMA2\%S), and $\beta$-cell function (HOMA2\%B) indices were generated using this software. An ideal person of average weight aged < 35 years had 1 HOMA2IR and 100\% HOMA type $\beta$-cell activity. The serum insulin level was assayed using a solid-phase enzyme-linked immunosorbent assay (ELISA) kit based on the sandwich principle supplied by Calbiotech ${ }^{\circledR}$, China. Other biomarkers and their suppliers were IL-10 (Elabscience ${ }^{\circledR}$, Inc. CA, USA), MOR, KOR, and EM2 (Mybiosource ${ }^{\circledR}$, Inc. CA, USA), and IL-6 and $\beta E P$ (Melsin Medical Co, Jilin, China). The sensitivities of $\beta$-endorphins, MOR, KOR, endomorphin-2, and IL-6 ELISA kits were $0.1 \mathrm{pg} / \mathrm{ml}, 7.18 \mathrm{pg} / \mathrm{ml}, 1.0 \mathrm{ng} /$ $\mathrm{ml}, 0.33 \mathrm{pg} / \mathrm{ml}$, and $0.1 \mathrm{pg} / \mathrm{ml}$, respectively. All measured concentrations were greater than their assay sensitivities. All intra-assay coefficients of variation were $<10.0 \%$. The absorbances of the microplates were measured by a microplate reader supplied by BioTek, Guangzhou, China. Serum CRP was measured using a kit supplied by Spinreact ${ }^{\circledR}$, Spain, using a test based on the latex agglutination principle. 


\section{Statistical analysis}

Analysis of variance (ANOVA) was employed to assess the differences in all measured biomarkers between diagnostic categories, and the $\chi^{2}$ test was used to compare the proportions and nominal variables. The associations among variables were computed using Pearson's product-moment and Spearman's rank-order correlation coefficient. The multivariate general linear model (GLM) analysis was used to delineate the effects of diagnosis for the prediabetes $+I R$, prediabetes $-I R$, and control groups while controlling the background variables, including age and sex. Protected LSD tests were used to check pairwise comparisons among treatment means. The model-generated estimated marginal mean (SE) values were computed after adjusting for covariates. Multiple regression analysis was used to delineate the significant biomarkers associated with the prediabetes+IR, and the results were checked for multicollinearity (tolerance and VIF values) and homoscedasticity (White and Breusch-Pagan tests). The binary logistic regression analysis was used to delineate the essential explanatory variables that predict prediabetes (versus control as the reference group). The data were subjected to $\ln$ transformation to normalize the measured biomarkers' data distribution (tested using the Kolmogorov-Smirnov test). However, the nonlinearity of any biomarker's mean and variance is a predictable source of variability that is eliminated using $z$ scores. The natural logarithm of the relevant $z$ unit scores was computed to transform the nonparametric variables into normally distributed components and apply the statistical analysis as a linear group. All tests were two-tailed, and a p-value $<0.05$ was used for statistical significance. All statistical analyses were performed using the IBM SPSS windows version 25, 2017. Odds ratios (OR) and 95\% confidence intervals $(\mathrm{CI})$ for unfavorable glycemic status by study factors were calculated.

\section{Results}

\section{Sociodemographic data}

Table 1 shows the sociodemographic data of the prediabetes-IR, prediabetes+IR, and healthy control groups. No significant difference was observed in age, BMI, sex ratio, and marital status among the study groups.

A significant increase $(\mathrm{p}<0.05)$ in TC, TG, VLDLc, and LDLc and a significant decrease in HDLc was observed in the prediabetes+IR group compared with the control group. No such difference was observed between the prediabetes $-I R$ and the prediabetes+IR groups. The atherogenic indices (TC/HDLc and LDLc/HDLc) were significantly different among the three study groups, and the scores followed the order: prediabetes $+\mathrm{IR}>$ prediabetes - IR $>$ controls. The TG/HDLc showed a significant increase in the prediabetes+IR group compared with the control group.

No significant difference was observed in the levels of the ratios of opioids to their receptors zLn $(\beta E P /$ MOR) and zLn (EM2/KOR) among the study groups. The level of other opioids in the prediabetes groups was higher than that in the control group: $\mathrm{zLn} \beta E \mathrm{P}(\mathrm{F}=6.834$, $\mathrm{df}=2 / 175, \mathrm{p}=0.002), \mathrm{zLnMOR}(\mathrm{F}=4.087, \mathrm{df}=2 / 175$, $\mathrm{p}=0.024), \mathrm{zLnEM} 2(\mathrm{~F}=6.615, \mathrm{df}=2 / 175, \mathrm{p}=0.002)$, and $\mathrm{zLnKOR}(\mathrm{F}=3.964, \mathrm{df}=2 / 175, \mathrm{p}=0.031)$.

Serum IL-10 was significantly different among the three study groups $(\mathrm{F}=9.362, \mathrm{df}=2 / 175, \mathrm{p}<0.001)$, and the score followed the order: prediabetes $+\mathrm{IR}>$ prediabetes $-I R>$ controls. zLnIL- 6 was significantly increased in the prediabetes groups than the control group, whereas no such difference was observed between the prediabetes subgroups.

The IR parameters, namely, glucose $(\mathrm{F}=49.734$, $\mathrm{df}=2 / 175, \mathrm{p}<0.001)$, insulin $(\mathrm{F}=256.628, \mathrm{df}=2 / 175$, $\mathrm{p}<0.001), \quad \mathrm{I} / \mathrm{G} \quad(\mathrm{F}=52.921, \quad \mathrm{df}=2 / 175, \quad \mathrm{p}<0.001)$, HOMA2\%S $(\mathrm{F}=174.254, \mathrm{df}=2 / 175, \mathrm{p}<0.001)$, and HOMA2IR $(\mathrm{F}=303.865, \mathrm{df}=2 / 175, \mathrm{p}<0.001)$, followed the order: controls $<$ prediabetes $-\mathrm{IR}<$ prediabetes $+\mathrm{IR}$. The HbA1c\% in the prediabetes-IR and the prediabetes+IR groups was higher than that in the control group $(\mathrm{F}=132.746, \mathrm{df}=2 / 175, \mathrm{p}<0.001)$. zLnHOMA2\%B showed no significant difference among the study groups $(\mathrm{F}=0.764, \mathrm{df}=2 / 175, \mathrm{p}=0.469)$.

\section{Differences in the biomarkers between the study groups}

In the entire study group, significant correlations were observed between the zLnMOR and the following parameters: IL-10 $(\mathrm{r}=0.306, \mathrm{p}=0.017)$, zLnKOR $(\mathrm{r}=0.311, \mathrm{p}=0.016)$, and zLnIL-6 $(\mathrm{r}=0.368, \mathrm{p}=0.004)$. zLnKOR was correlated with IL-6 $(\mathrm{r}=0.451, \mathrm{p}<0.001)$ and $\mathrm{zLnEM} 2$ with $(\mathrm{r}=0.377, \mathrm{p}=0.003)$.

\section{Multivariate GLM analysis}

Table 2 displays the multivariate GLM analysis outcomes comparing the measured biomarkers' differences among the three study groups while adjusting for age, BMI, sex, physical activity, IR parameters, and smoking. Significant differences $(p=0.040)$ were observed in the biomarkers among the groups with an effect size of 0.198 , whereas the other covariates had no significant effects $(p>0.05)$. The tests for between-subject effects in Table 2 and the results in Table 3 showed the SE values and indicated that all eight biomarkers of the patients with prediabetes were significantly higher than those of the control group. Furthermore, the IL-10, zLnßEP, zLnMOR, and zLnEM2 in the prediabetes subgroups were significantly higher than those in the control group. Among all the examined biomarkers, zLn $\beta E P$ had the highest effect on the diagnosis 
Table 1 Demographic and clinical data of healthy controls $(\mathrm{HC})$ and Prediabetes-IR versus Prediabetes+IR groups

\begin{tabular}{|c|c|c|c|c|c|c|}
\hline Parameter & $\begin{array}{l}\text { Control }^{A} \\
\mathrm{~N}=58\end{array}$ & $\begin{array}{l}\text { Prediabetes }-\mathrm{IR}^{\mathrm{B}} \\
\mathrm{N}=60\end{array}$ & $\begin{array}{l}\text { Prediabetes }+\mathrm{IR}^{\mathrm{C}} \\
\mathrm{N}=60\end{array}$ & $F / X^{2}$ & df & $p$ \\
\hline $\operatorname{Sex}(F / M)$ & $28 / 30$ & $28 / 32$ & $27 / 33$ & 0.364 & 2 & 0.552 \\
\hline Age year & $36.67 \pm 10.03$ & $35.03 \pm 11.44$ & $37.9 \pm 11.88$ & 0.499 & $2 / 175$ & 0.609 \\
\hline $\mathrm{BMI} \mathrm{kg} / \mathrm{m}^{2}$ & $26.39 \pm 3.72$ & $27.76 \pm 4.01$ & $27.63 \pm 5.14$ & 0.909 & $2 / 175$ & 0.407 \\
\hline Smoking $(\mathrm{Y} / \mathrm{N})$ & $17 / 41$ & $18 / 42$ & $19 / 41$ & 0.321 & 2 & 0.714 \\
\hline Marital status (M/S) & $33 / 25$ & $31 / 29$ & $36 / 24$ & 1.308 & 2 & 0.067 \\
\hline Physical activity (Y/N) & $21 / 37$ & $20 / 40$ & $18 / 42$ & 1.412 & 2 & 0.056 \\
\hline $\mathrm{TC} \mathrm{mM}$ & $4.07 \pm 0.59^{c}$ & $4.42 \pm 0.56$ & $4.72 \pm 0.70^{\mathrm{A}}$ & 8.288 & $2 / 175$ & 0.001 \\
\hline TG mM & $1.40 \pm 0.14^{c}$ & $1.49 \pm 0.17$ & $1.57 \pm 0.36^{\mathrm{A}}$ & 3.701 & $2 / 175$ & 0.029 \\
\hline VLDLc mM & $0.64 \pm 0.07^{C}$ & $0.68 \pm 0.08$ & $0.72 \pm 0.16^{\mathrm{A}}$ & 3.701 & $2 / 175$ & 0.029 \\
\hline HDLc mM & $1.12 \pm 0.11^{C}$ & $1.06 \pm 0.14$ & $0.99 \pm 0.13^{\mathrm{A}}$ & 6.789 & $2 / 175$ & 0.002 \\
\hline LDLc mM & $2.32 \pm 0.60^{c}$ & $2.69 \pm 0.58$ & $3.01 \pm 0.74^{\mathrm{A}}$ & 8.725 & $2 / 175$ & $<0.001$ \\
\hline $\mathrm{TC} / \mathrm{HDLC}$ & $3.69 \pm 0.64^{B, C}$ & $4.27 \pm 0.81^{A, C}$ & $4.81 \pm 0.80^{A, B}$ & 16.512 & $2 / 175$ & $<0.001$ \\
\hline $\mathrm{TG} / \mathrm{HDLC}$ & $1.27 \pm 0.19^{c}$ & $1.44 \pm 0.26$ & $1.61 \pm 0.42^{\mathrm{A}}$ & 9.298 & $2 / 175$ & $<0.001$ \\
\hline LDLC/HDLC & $2.11 \pm 0.60^{B, C}$ & $2.61 \pm 0.75^{A, C}$ & $3.07 \pm 0.81^{\mathrm{A}, \mathrm{B}}$ & 13.214 & $2 / 175$ & $<0.001$ \\
\hline zLn IL-6 & $-0.35 \pm 1.15^{B, C}$ & $0.16 \pm 0.90^{\mathrm{A}}$ & $0.19 \pm 0.86^{\mathrm{A}}$ & 4.562 & $2 / 175$ & 0.019 \\
\hline IL-10 pg/ml & $7.9 \pm 2.27^{B, C}$ & $11.46 \pm 4.52^{\mathrm{A}, \mathrm{C}}$ & $14.08 \pm 8.19^{\mathrm{A}, \mathrm{B}}$ & 9.362 & $2 / 175$ & $<0.001$ \\
\hline$z L n \beta E P$ & $-0.50 \pm 0.39^{\mathrm{B}, \mathrm{C}}$ & $0.37 \pm 1.39^{A}$ & $0.13 \pm 076^{A}$ & 6.834 & $2 / 175$ & 0.002 \\
\hline zLn MOR & $-0.34 \pm 1.15^{B, C}$ & $0.19 \pm 0.96^{\mathrm{A}}$ & $0.15 \pm 0.81^{\mathrm{A}}$ & 4.087 & $2 / 175$ & 0.024 \\
\hline zLn (BEP/MOR) & $-0.09 \pm 1.11$ & $0.10 \pm 1.02$ & $0.01 \pm 0.87$ & 0.279 & $2 / 175$ & 0.757 \\
\hline zLn EM2 & $-0.50 \pm 0.89^{B, C}$ & $0.16 \pm 0.98^{\mathrm{A}}$ & $0.34 \pm 0.964^{\mathrm{A}}$ & 6.615 & $2 / 175$ & 0.002 \\
\hline zLn KOR & $-0.35 \pm 1.20^{B, C}$ & $-0.21 \pm 1.14^{\mathrm{A}}$ & $0.14 \pm 0.64^{\mathrm{A}}$ & 3.964 & $2 / 175$ & 0.031 \\
\hline zLn (EM2/KOR) & $-0.15 \pm 1.14$ & $-0.038 \pm 0.94$ & $0.19 \pm 0.90$ & 0.888 & $2 / 175$ & 0.415 \\
\hline $\mathrm{HbA1c} \%$ & $5.01 \pm 0.43^{B, C}$ & $6.02 \pm 0.2^{A}$ & $6.17 \pm 0.2^{A}$ & 132.746 & $2 / 175$ & $<0.001$ \\
\hline Glucose mM & $5 \pm 0.71^{B, C}$ & $5.92 \pm 0.59^{A, C}$ & $6.49 \pm 0.39^{\mathrm{A}, \mathrm{B}}$ & 49.734 & $2 / 175$ & $<0.001$ \\
\hline Insulin pM & $68.54 \pm 10.79^{B, C}$ & $100.74 \pm 13.64^{A, C}$ & $140.48 \pm 12.38^{\mathrm{A}, \mathrm{B}}$ & 256.628 & $2 / 175$ & $<0.001$ \\
\hline I/G mM & $14.07 \pm 3.40^{B, C}$ & $17.12 \pm 2.46^{\mathrm{A}, \mathrm{C}}$ & $21.79 \pm 2.84^{\mathrm{A}, \mathrm{B}}$ & 52.921 & $2 / 175$ & $<0.001$ \\
\hline zLnHOMA2\%B & $0.13 \pm 1.39$ & $0.18 \pm 0.84$ & $0.05 \pm 0.63$ & 0.764 & $2 / 175$ & 0.469 \\
\hline HOMA2\%S & $80.72 \pm 13.82^{B, C}$ & $52.63 \pm 7.51^{A, C}$ & $36.85 \pm 2.80^{A, B}$ & 174.254 & $2 / 175$ & $<0.001$ \\
\hline HOMA2IR & $1.27 \pm 0.19^{B, C}$ & $1.94 \pm 0.27^{\mathrm{A}, \mathrm{C}}$ & $2.73 \pm 0.22^{A, B}$ & 303.865 & $2 / 175$ & $<0.001$ \\
\hline
\end{tabular}

$A, B, C$ Pairwise comparisons between group means

zLn: z-score of the natural logarithm; FPG: fasting plasma glucose; TC: serum total cholesterol; TG: serum triglycerides; VLDLc: very-low-density lipoproteins; HDLc: high-density lipoproteins; LDLc: Low-density lipoproteins; IL: interleukin; KOR: K-opioid receptor; MOR: $\mu$ opioid receptor; EM2: Endomorphin-2; $\beta E P$ : $\beta$-endorphin; BMI: Body mass index; HOMA2IR: homeostasis model assessment 2 of insulin resistance; HOMA2\%S: homeostasis model assessment 2 of insulin sensitivity percentage; HOMA2\%B: homeostasis model assessment 2 of beta-cell function percentage; IR: insulin resistance (HOMA2IR $>2.5$ )

of prediabetes $(\mathrm{F}=5.128, \mathrm{df}=2 / 175, \mathrm{p}=0.027$, partial $\left.\eta^{2}=0.067\right)$.

Table 4 shows the results of two binary logistic regression analyses examining the best predictors of prediabetes (versus controls) and prediabetes-IR (versus prediabetes+IR) by using an automatic stepwise method with biomarkers as explanatory variables while allowing the effects of other cofounders (age, sex, and smoking). The first regression analysis showed that prediabetes was best predicted by increased levels of IL-10, zLnßEP, and zLnEM2 $\left(x^{2}=38.122, \mathrm{df}=7, \mathrm{p}<0.001\right.$, Nagelkerke $=0.480)$ with an accuracy of $76.7 \%$, sensitivity of $85.0 \%$, and specificity of $75.6 \%$. The second regression analysis showed that the combination of
IL-10 and zLnEM2/KOR were the best predictors of prediabetes+IR versus prediabetes-IR $\left(\mathrm{X}^{2}=14.780\right.$, $\mathrm{df}=7, \mathrm{p}=0.031$, Nagelkerke $=0.364$ ) with an accuracy of $71.2 \%$, sensitivity of $74.4 \%$, and specificity of $72.7 \%$.

\section{Prediction of symptom domains by biomarkers}

Table 5 shows different stepwise multiple regression analyses with the IR parameters as dependent variables and the eight biomarkers as explanatory variables while allowing the effects of age and sex. Regression \#1 showed that the regression could explain $21.1 \%$ of the variance in the total FPG on IL-10, zLnKOR, and zLn (EM2/KOR). Regressions \#2, \#4, \#5, and \#6 showed that the same variables explained a considerable part of the variance in 
Table 2 Results of multivariate GLM analysis showing the associations between biomarkers and diagnosis of prediabetes while adjusting for background variables

\begin{tabular}{|c|c|c|c|c|c|c|}
\hline Type & Dependent variable & Explanatory variable & $\mathrm{F}$ & df & p & Partial $\eta^{2}$ \\
\hline \multirow[t]{14}{*}{ Multivariate } & \multirow{14}{*}{ 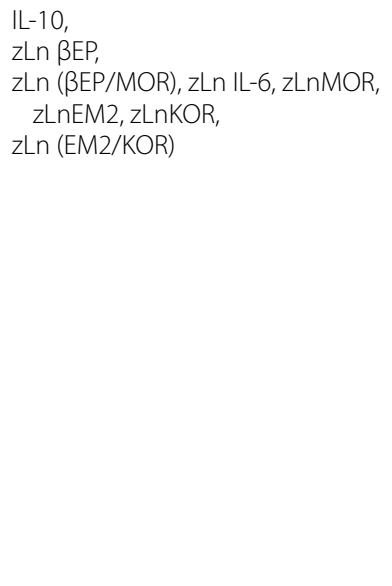 } & Diagnosis & 2.203 & $16 / 212$ & 0.045 & 0.192 \\
\hline & & Sex & 0.450 & $8 / 156$ & 0.867 & 0.046 \\
\hline & & Age & 1.138 & $8 / 156$ & 0.351 & 0.109 \\
\hline & & BMI & 1.803 & $8 / 156$ & 0.102 & 0.163 \\
\hline & & Smoking & 0.604 & $8 / 156$ & 0.750 & 0.061 \\
\hline & & Physical activity & 0.798 & $8 / 156$ & 0.612 & 0.084 \\
\hline & & $\mathrm{HbA1c}$ & 1.076 & $8 / 156$ & 0.389 & 0.104 \\
\hline & & Glucose & 0.801 & $8 / 156$ & 0.590 & 0.079 \\
\hline & & Insulin & 0.851 & $8 / 156$ & 0.550 & 0.084 \\
\hline & & $\mathrm{I} / \mathrm{G}$ & 0.968 & $8 / 156$ & 0.462 & 0.094 \\
\hline & & HOMA2\%S & 0.495 & $8 / 156$ & 0.835 & 0.051 \\
\hline & & HOMA2IR & 0.841 & $8 / 156$ & 0.558 & 0.083 \\
\hline & & zLnHOMA2\%B & 1.177 & $8 / 156$ & 0.328 & 0.112 \\
\hline & & Dyslipidemia & 0.020 & $8 / 156$ & 0.966 & 0.001 \\
\hline \multirow{8}{*}{$\begin{array}{l}\text { Tests of Between-Sub- } \\
\text { jects Effects }\end{array}$} & Diagnosis & $\mathbb{I L}-10$ & 2.102 & $2 / 163$ & 0.152 & 0.029 \\
\hline & Diagnosis & $z \operatorname{Ln} \beta E P$ & 5.128 & $2 / 163$ & 0.027 & 0.067 \\
\hline & Diagnosis & zLn(ßEP/MOR) & 0.884 & $2 / 163$ & 0.350 & 0.012 \\
\hline & Diagnosis & zLn IL-6 & 0.202 & $2 / 163$ & 0.654 & 0.003 \\
\hline & Diagnosis & zLnMOR & 1.131 & $2 / 163$ & 0.291 & 0.016 \\
\hline & Diagnosis & zLnEM2 & 0.003 & $2 / 163$ & 0.957 & 0.001 \\
\hline & Diagnosis & zLnKOR & 3.745 & $2 / 163$ & 0.057 & 0.050 \\
\hline & Diagnosis & zLn (EM2/KOR) & 2.213 & $2 / 163$ & 0.141 & 0.030 \\
\hline
\end{tabular}

zLn: z-score of the natural logarithm; FPG: fasting plasma glucose; IL: interleukin; KOR: K-opioid receptor; MOR: $\mu$ opioid receptor; EM2: Endomorphin-2; $\beta E P$ : $\beta$-endorphin

Table 3 Model-generated estimated marginal means values (SE) of the biomarkers in prediabetes (versus healthy controls) and prediabetes $-I R$ versus prediabetes+IR and healthy controls

\begin{tabular}{|c|c|c|c|}
\hline Biomarkers & Control $^{A}$ & Prediabetes- $-\mathrm{R}^{\mathrm{B}}$ & Prediabetes $+\mathbf{I R}^{C}$ \\
\hline IL-10 & $7.981(1.062)^{B, C}$ & $11.461(1.026)^{\mathrm{A}}$ & $14.082(1.026)^{A}$ \\
\hline$z \operatorname{Ln} \beta E P$ & $12.146(2.308)^{B, C}$ & $23.652(2.230)^{A}$ & $20.638(2.230)^{A}$ \\
\hline zLn ( $\beta E P / M O R)$ & $5.362(0.677)$ & $5.976(0.654)$ & $5.572(0.654)$ \\
\hline$z \operatorname{Ln} \mid \mathrm{LL}-6$ & $0.314(-0.187)$ & $0.157(0.180)$ & $0.194(0.180)$ \\
\hline zLnMOR & $0.431(-0.180)^{B, C}$ & $0.194(0.174)^{A}$ & $0.149(0.174)^{A}$ \\
\hline zLnEM2 & $0.518(-0.180)^{B, C}$ & $0.163(0.174)^{A}$ & $0.338(0.174)^{A}$ \\
\hline zLnKOR & $0.362(-0.186)$ & $0.213(0.180)$ & $0.140(0.180)$ \\
\hline zLn (EM2/KOR) & $0.158(-0.191)$ & $0.038(-0.185)$ & $0.188(0.185)$ \\
\hline
\end{tabular}

$A, B, C$ Pairwise comparisons between group means

zLn: z-score of the natural logarithm, IL: interleukin; KOR: k-opioid receptor; MOR: $\mu$ opioid receptor; EM2: Endomorphin-2; $\beta$ EP: $\beta$-endorphin

insulin (22.4\%), HbA1c (29.0\%), HOMA2IR (29.3\%), and HOMA2\%S (29.7\%). Regression \#3 showed that $13.0 \%$ of the variance in the I/G ratio was explained by IL-10.

The subjects with prediabetes had dyslipidemia, and not all of them underwent the IR state. The IL-6, IL-10, $\beta E P$, MOR, and EM2 were higher in the prediabetes. MOR was correlated with IL-10 and KOR. Prediabetes + IR can be predicted by the increased levels of IL-10, $\beta E P$, and EM2 and by the combination of IL-10 and EM2/KOR with good sensitivity and specificity.

\section{Discussion}

The first significant result is the increased atherogenic indices and dyslipidemia state in the prediabetes +IR group compared to the controls, indicating the negative effect of elevated IR on lipid metabolism (Table 1). IR may also alter systemic lipid metabolism and endothelial dysfunction that ultimately contribute to dyslipidemia and atherosclerotic plaque formation $[29,30]$. IR in the myocardium causes damage through a modification of the signal transduction, impaired regulation of the substrates' metabolism, and variation in the delivery of myocardium substrates [29,31]. These heart muscles' changes are associated with the presence of increased IR in the prediabetes patients and absent in the prediabetes-IR group.

The increase of the endogenous opioids and their receptors in the prediabetes subgroups compared with the controls suggests the dependence of these parameters on the state of the glucose metabolism rather than 
Table 4 Results of two different binary logistic regression analyses with prediabetes (versus healthy controls) and Prediabetes-IR versus Prediabetes+IR as dependent variables and the biomarkers as explanatory variables

\begin{tabular}{lllllllll}
\hline Dichotomies & Explanatory variables & B & SE & Wald & df & $\mathbf{p}$ & OR & $\mathbf{9 5 \%}$ Cl \\
\hline Prediabetes/Controls & IL-10 & 0.359 & 0.128 & 7.876 & 1 & 0.005 & 1.431 & $1.114-1.839$ \\
& ZLnßEP & 0.316 & 0.137 & 5.311 & 1 & 0.021 & 1.372 & $1.048-1.795$ \\
Prediabetes-IR/Prediabetes+IR & ZLnEM2 & 0.846 & 0.396 & 4.569 & 1 & 0.033 & 2.331 & $1.073-5.063$ \\
& IL-10 & 0.618 & 0.05 & 2.505 & 1 & 0.043 & 1.083 & $0.981-1.195$ \\
& zLnEM2/KOR & 0.555 & 0.433 & 4.846 & 1 & 0.024 & 2.611 & $1.187-3.947$ \\
\hline
\end{tabular}

zLn: z-score of the natural logarithm; IL: interleukin; KOR: K-opioid receptor; MOR: $\mu$-opioid receptor; EM2: Endomorphin-2; $\beta E P$ : $\beta$-endorphin; IR: insulin resistance (HOMA2IR $>2.5$ )

Table 5 Results of multiple regression analysis with IR parameters as dependent variables and biomarkers as explanatory variables

\begin{tabular}{|c|c|c|c|c|c|c|c|c|}
\hline Dependent variables & Explanatory variables & $\beta$ & $\mathbf{t}$ & $p$ & $\mathbf{F}_{\text {model }}$ & df & $p$ & $\mathrm{R}^{2}$ \\
\hline \multirow[t]{4}{*}{ 1. FPG } & Model & & & & 3.142 & $7 / 82$ & 0.005 & 0.211 \\
\hline & $\mathrm{IL}-10$ & 0.279 & 2.661 & 0.009 & & & & \\
\hline & zLnKOR & 0.374 & 2.625 & 0.010 & & & & \\
\hline & zLn(EM2/KOR) & 0.302 & 2.537 & 0.130 & & & & \\
\hline \multirow[t]{4}{*}{ 2. Insulin } & Model & & & & 4.669 & $7 / 82$ & $<0.001$ & 0.224 \\
\hline & $\mathrm{IL}-10$ & 0.397 & 3.973 & $<0.001$ & & & & \\
\hline & zLnKOR & 0.339 & 2.498 & 0.015 & & & & \\
\hline & zLn(EM2/KOR) & 0.271 & 2.393 & 0.019 & & & & \\
\hline \multirow[t]{2}{*}{ 3. $1 / \mathrm{G}$} & Model & & & & 2.907 & $7 / 82$ & 0.009 & 0.130 \\
\hline & IL-10 & 0.322 & 3.041 & 0.003 & & & & \\
\hline \multirow[t]{4}{*}{ 4. $\mathrm{HbA} 1 \mathrm{C}$} & Model & & & & 6.200 & $7 / 82$ & $<0.001$ & 0.290 \\
\hline & $\mathrm{IL}-10$ & 0.318 & 3.333 & 0.001 & & & & \\
\hline & zLnKOR & 0.386 & 2.977 & 0.004 & & & & \\
\hline & zLn(EM2/KOR) & 0.356 & 3.284 & 0.002 & & & & \\
\hline \multirow[t]{4}{*}{ 5. HOMA2IR } & Model & & & & 4.809 & $7 / 82$ & $<0.001$ & 0.293 \\
\hline & $\mathrm{IL}-10$ & 0.401 & 4.029 & $<0.001$ & & & & \\
\hline & zLnKOR & 0.355 & 2.624 & 0.010 & & & & \\
\hline & zLn(EM2/KOR) & 0.280 & 2.485 & 0.015 & & & & \\
\hline \multirow[t]{4}{*}{ 6. HOMA2\%S } & Model & & & & 4.836 & $7 / 82$ & $<0.001$ & 0.297 \\
\hline & $\mathrm{IL}-10$ & -0.348 & -3.497 & 0.001 & & & & \\
\hline & zLnKOR & -0.371 & -2.749 & 0.007 & & & & \\
\hline & zLn(EM2/KOR) & -0.290 & -2.577 & 0.012 & & & & \\
\hline
\end{tabular}

zLn: z-score of the natural logarithm, FPG: fasting plasma glucose, IL: interleukin; KOR: k-opioid receptor; MOR: $\mu$ opioid receptor; EM2: Endomorphin-2; $\beta$ EP: $\beta$-endorphin; HOMA2IR: homeostasis model assessment 2 of insulin resistance, HOMA2\%S: homeostasis model assessment 2 of insulin sensitivity percentage; HOMA2\%B: homeostasis model assessment 2 of beta-cell function percentage

its dependence on the insulin hormone response. To our knowledge, these results are the first study that measured endogenous opioids in prediabetes disorder. Previous research examined the IR parameters with opioid peptides and receptors in other diseases [19, 32, 33]. However, there is no definite explanation for the associations between IR and EOS molecules. Among the suggested explanations, MOR is enhanced in insulin-sensitive tissues, such as the skeletal muscle, resulting in a reversal of insulin-stimulated glucose disposal impairment in genetically obese rats through exercise training [19]. This
IR enhancement is associated with increased B-endorphin secretion, thereby enhancing the post-receptor and insulin signaling cascade, including the downstream phosphatidylinositol-3 kinase signaling pathway involved in glucose translocation [18, 19]. Interestingly, in the IR stage, brain damage and disturbance of white matter occur without overt diabetes, and these structural changes may cause early cognitive dysfunction [34] and secrete endogenous peptides into the bloodstream and increase their rates. The hypothesis is the mutual interaction between pro-/ inflammatory cytokines, EOS 
peptides, and their receptors with insulin secretion and synthesis, as seen in Fig. 1.

EOPs administer the $\beta$-cell endocrine function resulted in insulin secretion through paracrine and intracrine mechanisms within the pancreas [21, 35]. Increasing the release of $\beta E P$ from the adrenal gland may stimulate peripheral opioid MOR to increase muscle glucose transporter expression and/or reduce gene-level hepatic gluconeogenesis, thereby increasing the use of glucose in peripheral tissues to improve severe hyperglycemia [18]. Therefore, increased opioid production locally results in the release of insulin from the pancreas. IR results from hepatic insulin receptor downregulation, thereby increasing the insulin levels in peripheral blood $[5,17]$.

The peptides and receptors of EOS in the brain areas control appetite [36] and mood and are associated with mood disorders [37]. MOR and KOR appear to compensate for the inclusion by the nucleus of specific food intakes [38]. Activation of $\beta$-cells and subsequent regulation of insulin secretion and glucose metabolism by MOR is mediated via sympathetic innervation [39]. Treatment with the selective KOR agonist diminishes the blood glucose level dramatically [40].

For prediabetes subjects, the elevation of EM2 could be due to an increase in their release in response to beta cells' potential injury. EM2 can preserve the beta-cell islets in animal studies from the injury caused by streptozotocin, alloxan, and hydrogen peroxide [40]. EM2 improves islet viability and increases the cell supernatant's insulin production after streptozotocin and stimulation by alloxan. These results indicated that endomorphins might have protective effects on oxidative injury to islet cells [40].

The prevalence of these differences in prediabetes groups and controls should be considered when finding a new treatment target to prevent prediabetes from progressing into T2DM. Between the three study groups, serum IL-10 was significantly different, and the score followed the order: controls $<$ prediabetes $-I R<$ prediabetes + IR. In a previous study, relative to

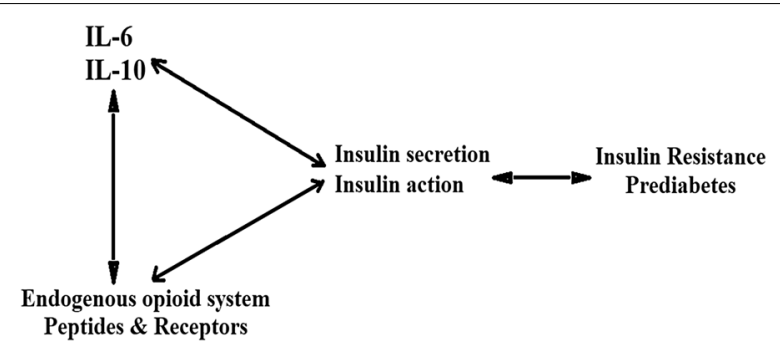

Fig. 1 Potential mutual interaction between immune system, EOS peptides and insulin secretion and synthesis healthy controls [41], the serum IL-10 level is elevated in T2DM but not in prediabetes.

The present study has excluded the patients with positive CRP to ensure we have included only the patients free from overt inflammation. However, several studies documented the introduction of the Th1 cell subset and the causal involvement of this phenomenon in inflammation and IR in the diabetes mouse models [42]. In prediabetes groups, IL- 6 was significantly elevated compared to the control group, whereas there was no such difference between the prediabetes subgroups. IL- 6 showed no significant difference between the groups and controls for prediabetes [43]. Nonetheless, hyperglycemic/ hyperinsulinemic conditions [43] show increased IL-6, another pro-inflammatory marker. The findings showed significant associations between IL-10 and MOR, as well as between IL- 6 and KOR. Exogenous opioids inhibit the ability of macrophages, natural killer cells, and T-cells to in-vitro and animal models weaken the gut barrier [44]. Immune cells secrete endogenous opioid peptides connected to peripheral opioid receptors to alleviate inflammatory pain. The immune system and endogenous opioids are usually similarly co-operative [44]. IL-10 and MOR have a depression relationship [37], suggesting that, in addition to the possible correlation between immune and opioid systems, mood triggers such an interaction.

The second significant result was obtained from the multivariate GLM study, which excluded the covariate effects (age, BMI, sex, IR parameters, physical activity, and smoking) to compare the parameters according to the diagnostic form (Table 2). Around 20\% (0.198) of immune-opioid biomarker values can be clarified by prediabetes and IR. Based on Tables 2 and 3 (SE) findings, all eight biomarkers in patients with prediabetes were significantly higher compared with the controls. Of all of the biomarkers tested, $\mathrm{zLn} \beta E P$ had the most significant effect on prediabetes diagnosis. $\beta E P$ cells have been seen in areas near pancreatic $\beta$-cells, and opioids increase insulin secretion [45]. Increased circulating $\beta E P$ is associated with enhancing IR to ameliorate the post-receptor insulin signaling cascade and enhance insulin sensitivity through peripheral motivation [19]. By sharing insulin release, MOR controls body weight, showing a novel target for new diabetes treatments [21]. The endogenous opioid system in vitro negatively regulates insulin secretion from isolated islets of Langerhans [46]. Additionally, some groups recorded the dual stimulative/inhibitory effect of $\beta$-endorphin on insulin secretion depending on dose, obesity, or circulating glucose level [47].

MORs function as a part of the complex opioid mechanism, mediating the effects of endogenous opioids such as EM2 and various exogenous opioid agonists [48]. MOR participates in glucose homeostasis by adversely 
controlling glucose tolerance by inhibiting insulin release from the $\beta$-cell and the $\beta$-cell mass [21]. In muscle tissues and cells, an association occurs between MOR and IRS [32]. It is found that opioid-induced insulin secretion may be based on G-protein independent mechanisms [49]. Based on a linear regression analysis, $\beta E P$ is the strongest protein associated with the $\beta$-cell function [20].

The analyzes of binary logistic regression in Table 4 showed that the increased rates of the combination of IL-10, zLn $\beta E P$, and zLnEM2 could be used with reasonable precision to distinguish prediabetes $+I R$ from other classes (76.7\%). Another collection of increased IL-10 and zLnEM2 / KOR can be used with reasonable precision $(71.2 \%)$ to predict prediabetes+IR. These findings further indicate the value in prediabetes+IR of these parameters and the close association with the immuneopioid system. EOS molecule production increases by acting on the pancreatic $\beta$-cells, increasing insulin secretion resulting in elevated insulin levels in the hepatic circulation. Increased insulin levels contribute to hepatic insulin receptors' downregulation, triggering, and sustaining hyperinsulinemia $[7,19]$. Considering that MOR's central stimulation impairs glucose tolerance and responsiveness to insulin and motivates hepatic gluconeogenesis [50], stimulation of peripheral MOR can improve IR in animals and provide a novel target for IR treatment [51]. MOR activation increases IL-6-induced IR by contrasting insulin sensitivity by specific insulin signals [52]. In contrast, KOR activation results in decreased levels of IL-6 [53].

The effect of the calculated biomarkers on the IR parameters is shown in Table 5. The regression on IL-10, zLnKOR, and zLn(EM2/KOR) will explain approximately one-fifth (21.1\%) of the variance in FPG. In subjects with obesity, elevated endogenous opiates can influence the insulin response to glucose through impaired or standard oral glucose tolerance tests [54]. The same changes explain a significant portion of the insulin variations, HbA1c, HOMA2IR, and HOMA2\%S. It is found that the decrease in the IR condition following a decrease in body weight has no significant effect on the $\beta E P$ level [55]. The independent parameters (FBG, leptin, and $\mathrm{HbA1C}$ ) linked well in healthy people because the beta cells were functioning correctly. Elevated blood glucose induces insulin concentrations' elevation when released from the healthy beta cells to maintain average blood glucose concentrations over long periods [56].

\section{Conclusion}

Most prediabetes subjects had an IR state, an elevation in the immune and opioid biomarkers, and dyslipidemia. Of all the biomarkers tested, $\beta E P$ has the highest diagnostic value for prediabetes. The immune system was activated in the prediabetes in an IR-dependent manner. Prediabetes+IR can be predicted using the increased rates of the IL-10, $\beta E P$, and EM2 mixture and a mixture of IL-10 and EM2/KOR with strong sensitivity and specificity. Therefore, we rejected the null hypothesis and confirmed intercorrelation between the immune system, EOS, and insulin in prediabetes.

\section{Limitations of the study}

The major limitation of the study is the relatively low number of participants. As no institution funded the work, the author could not measure other cytokines, opioids, and receptors to obtain a whole picture of these parameters' role in prediabetes.

\section{Abbreviations}

ANOVA: Analysis of variance; $\beta E P$ : $\beta$-Endorphin; BMI: Body mass index; Cl: Confidence intervals; CRP: C-reactive protein; DSM-IV-TR: Diagnostic and statistical manual of mental disorders, fourth edition, text revision; ELISA: Enzyme-linked immunosorbent assay; EM2: Endomorphin-2; FBG: Fasting blood glucose; EOS: Endogenous opioid system; GLM: General linear model; GLUT4: Glucose transporter 4; HbA1c: Glycated hemoglobin; HDLc: High-density lipoprotein cholesterol; HOMA2: Homeostasis model assessment version 2; HOMA\%B: Beta-cell function percentage; HOMA\%S: Insulin sensitivity percentage; IDE: Insulin-degrading enzyme; IL: Interleukin; IR: Insulin resistance; IRS: Insulin receptor substrate; KOR: $\mathrm{k}$-Opioid receptor; LDLc: Low-density lipoprotein cholesterol; MOR: $\mu$-Opioid receptor; OR: Odds ratios; SE: Standard error; Tc: Total cholesterol; TG: Triglycerides; VIF: Variance inflation factor; VLDLc: Verylow-density lipoprotein cholesterol; $x^{2}$ : Chi-squared.

\section{Acknowledgements}

I would like to express my sincere thanks and gratitude to Professor Hussein Al-Hakeim for the great advanced statistical analysis he did for the results of my research. I highly appreciate the great work of Asia Lab, in Najaf City, regarding the analysis of my samples.l thank all the volunteers for their contribution in the study.

\section{Authors' contributions}

SRM, as a sole author, has planned, wrote, and approved the final draft of the manuscript.

\section{Funding}

There was no specific funding for this specific study.

\section{Declarations}

\section{Ethics approval and consent to participate}

Ethics Committee of Medical Research at the College of Pharmacy /Hawler Medical University (HMU) has approved the current study. The reference No. of the ethical approval paper is HMU-PH-EC 191223/102. All procedures performed in a study involving human participants were under the ethical standards of the relevant national and institutional committees on human experimentation and with the Helsinki Declaration of 1975, as revised in 2013, and with the Ethics Committee of Medical Research at College of Pharmacy/ Hawler Medical University.

\section{Informed consent}

Written informed consent was taken from all the participants before participation in the current study. The potential subject informed of the right to refuse participation in the study or to withdraw consent to participate at any time without reprisal. 


\section{Consent for publication}

Yes.

\section{Competing interests}

The author declares no conflict of interests.

Received: 18 November 2020 Accepted: 20 May 2021 Published online: 07 June 2021

\section{References}

1. Buysschaert M, Bergman M. Definition of prediabetes. Med Clin 2011;95(2):289-97.

2. Control CfD, Prevention. National diabetes statistics report, 2020. Atlanta, GA: Centers for Disease Control and Prevention, US Department of Health and Human Services. 2020:12-5.

3. Association AD. 2. Classification and diagnosis of diabetes. Diabetes Care. 2017:40(Supplement 1):S11-24

4. Tang Q, Li X, Song P, Xu L. Optimal cut-off values for the homeostasis model assessment of insulin resistance (HOMA-IR) and prediabetes screening: developments in research and prospects for the future. Drug Discov Ther. 2015;9(6):380-5.

5. Petersen MC, Shulman Gl. Mechanisms of insulin action and insulin resistance. Physiol Rev. 2018;98(4):2133-223.

6. Khetan AK, Rajagopalan S. Prediabetes. Can J Cardiol. 2018;34(5):615-23.

7. Singh Y, Garg M, Tandon N, Marwaha RK. A study of insulin resistance by HOMA-IR and its cut-off value to identify metabolic syndrome in urban Indian adolescents. J Clin Res Pediat Endocrinol. 2013:5(4):245.

8. Ziaee A, Esmailzadehha N, Oveisi S, Ghorbani A, Ghanei L. The threshold value of homeostasis model assessment for insulin resistance in Qazvin Metabolic Diseases Study (QMDS): assessment of metabolic syndrome. JRHS J Res Health Sci. 2015:15:94-100.

9. Al-Hakeim HK, Abdulzahra MS. Correlation between glycated hemoglobin and Homa Indices in type 2 diabetes mellitus: prediction of betacell function from glycated hemoglobin/Korelacija Između Glikoliziranog Hemoglobina I Homa Indeksa U Dijabetes Melitusu Tipa 2: Predviđanje Funkcije Beta Ćelija Na Osnovu Glikoliziranog Hemoglobina. J Med Biochem. 2015;34(2):191-9.

10. Ruud J, Steculorum SM, Brüning JC. Neuronal control of peripheral insulin sensitivity and glucose metabolism. Nat Commun. 2017;8(1):1-12.

11. Grillo CA, Woodruff JL, Macht VA, Reagan LP. Insulin resistance and hippocampal dysfunction: disentangling peripheral and brain causes from consequences. Exp Neurol. 2019;318:71-7.

12. Macklin L, Griffith CM, Cai Y, Rose GM, Yan X-X, Patrylo PR. Glucose tolerance and insulin sensitivity are impaired in APP/PS1 transgenic mice prior to amyloid plaque pathogenesis and cognitive decline. Exp Gerontol. 2017:88:9-18.

13. De Felice FG. Alzheimer's disease and insulin resistance: translating basic science into clinical applications. J Clin Invest. 2013;123(2):531-9.

14. Bomfim TR, Forny-Germano L, Sathler LB, Brito-Moreira J, Houzel J-C, Decker $\mathrm{H}$, et al. An anti-diabetes agent protects the mouse brain from defective insulin signaling caused by Alzheimer's disease-associated $A \beta$ oligomers. J Clin Invest. 2012;122(4):1339-53.

15. Reijmer YD, Leemans A, Brundel M, Kappelle LJ, Biessels GJ. Disruption of the cerebral white matter network is related to slowing of information processing speed in patients with type 2 diabetes. Diabetes. 2013;62(6):2112-5.

16. Ekblad LL, Rinne JO, Puukka PJ, Laine HK, Ahtiluoto SE, Sulkava RO, et al. Insulin resistance is associated with poorer verbal fluency performance in women. Diabetologia. 2015;58(11):2545-53.

17. Tudurí E, Beiroa D, Stegbauer J, Fernø J, López M, Diéguez C, et al. Acute stimulation of brain mu opioid receptors inhibits glucose-stimulated insulin secretion via sympathetic innervation. Neuropharmacol. 2016;110:322-32.

18. Liu I, Cheng J. Mediation of endogenous $\beta$-endorphin in the plasma glucose-lowering action of herbal products observed in type 1-like diabetic rats. Evid Based Complement Alternat Med. 2011;2011:987876.

19. Cheng K-C, Asakawa A, Li Y-X, Liu IM, Amitani H, Cheng J-T, et al. Opioid $\mu$-receptors as new target for insulin resistance. Pharmacol Therapeut. 2013;139(3):334-40.
20. Curran AM, Scott-Boyer MP, Kaput J, Ryan MF, Drummond E, Gibney ER, et al. A proteomic signature that reflects pancreatic beta-cell function. PLOS ONE. 2018:13(8):e0202727.

21. Wen T, Peng B, Pintar JE. The MOR-1 opioid receptor regulates glucose homeostasis by modulating insulin secretion. Mol Endocrin. 2009;23(5):671-8

22. Najafipour $\mathrm{H}$, Beik $\mathrm{A}$. The impact of opium consumption on blood glucose, serum lipids and blood pressure, and related mechanisms. Front Physiol. 2016:7:436.

23. Asgary S, Sarrafzadegan N, Naderi G-A, Rozbehani R. Effect of opium addiction on new and traditional cardiovascular risk factors: do duration of addiction and route of administration matter? Lipids Health Dis. 2008;7(1):1-5

24. Vuong C, Van Uum SH, O'Dell LE, Lutfy K, Friedman TC. The effects of opioids and opioid analogs on animal and human endocrine systems. Endocr Rev. 2010;31(1):98-132.

25. Rehman K, Akash MSH, Liaqat A, Kamal S, Qadir MI, Rasul A. Role of interleukin-6 in development of insulin resistance and type 2 diabetes mellitus. Crit Rev Eukaryot Gene Expr. 2017;27(3):229-36.

26. Kurauti MA, Costa-Júnior JM, Ferreira SM, Santos GJ, Sponton CH, Carneiro EM, et al. Interleukin- 6 increases the expression and activity of insulindegrading enzyme. Sci Rep. 2017;7(1):1-12.

27. Sanjabi S, Zenewicz LA, Kamanaka M, Flavell RA. Anti-inflammatory and pro-inflammatory roles of TGF- $\beta, \mathrm{IL}-10$, and IL-22 in immunity and autoimmunity. Curr Opin Pharmacol. 2009;9(4):447-53.

28. Leon-Cabrera S, Arana-Lechuga Y, Esqueda-León E, Terán-Pérez G, Gonzalez-Chavez A, Escobedo G, et al. Reduced systemic levels of IL-10 are associated with the severity of obstructive sleep apnea and insulin resistance in morbidly obese humans. Mediators Inflamm. 2015;2015:493409.

29. Ormazabal V, Nair S, Elfeky O, Aguayo C, Salomon C, Zuñiga FA. Association between insulin resistance and the development of cardiovascular disease. Cardiovas Diabetol. 2018;17(1):1-14.

30. Semple RK, Sleigh A, Murgatroyd PR, Adams CA, Bluck L, Jackson S, et al, Postreceptor insulin resistance contributes to human dyslipidemia and hepatic steatosis. J Clin Invest. 2009;119(2):315-22.

31. Zheng L, Li B, Lin S, Chen L, Li H. Role and mechanism of cardiac insulin resistance in occurrence of heart failure caused by myocardial hypertrophy. Aging. 2019;11(16):6584

32. Chen X, Wang L, Fan S, Song S, Min H, Wu Y, et al. Puerarin acts on the skeletal muscle to improve insulin sensitivity in diabetic rats involving $\mu$-opioid receptor. Eur J Pharmacol. 2018;818:115-23.

33. Qazmooz HA, Smesam HN, Mousa RF, Al-Hakeim HK, Maes M. Trace element, immune and opioid biomarkers of unstable angina, increased atherogenicity and insulin resistance: results of machine learning. J Trace Elem Med Biol. 2021;64:126703.

34. Willette AA, Xu G, Johnson SC, Birdsill AC, Jonaitis EM, Sager MA, et al. Insulin resistance, brain atrophy, and cognitive performance in late middle-aged adults. Diabetes Care. 2013;36(2):443-9.

35. Boettcher B, Seeber B, Leyendecker G, Wildt L. Impact of the opioid system on the reproductive axis. Fertil Steril. 2017;108(2):207-13.

36. Tyagi A, Daliri EB-M, Kwami Ofosu F, Yeon S-J, Oh D-H. Food-derived opioid peptides in human health: a review. Int J Mol Sci. 2020;21(22):8825.

37. Al-Fadhel SZ, Al-Hakeim HK, Al-Dujaili AH, Maes M. IL-10 is associated with increased mu-opioid receptor levels in major depressive disorder. Eur Psychiatry. 2019:57:46-51.

38. Caref K, Nicola SM. Endogenous opioids in the nucleus accumbens promote approach to high-fat food in the absence of caloric need. Elife. 2018;7:e34955

39. Tudurí E, Beiroa D, Stegbauer J, Fernø J, López M, Diéguez C, et al. Acute stimulation of brain mu opioid receptors inhibits glucose-stimulated insulin secretion via sympathetic innervation. Neuropharmacology. 2016:110(Pt A):322-32.

40. Tian L, Liu J, Sun X, Gao C, Fan Y, Guo Q. A protective effect of endomorphins on the oxidative injury of islet. Exp Clin Endocr Diabetes. 2010;118(08):467-72

41. Lopez YON, Garufi G, Seyhan AA. Altered levels of circulating cytokines and microRNAs in lean and obese individuals with prediabetes and type 2 diabetes. Mol Biosyst. 2017;13(1):106-21.

42. Kornete M, Mason E, Piccirillo CA. Immune regulation in T1D and T2D: prospective role of Foxp3 + Treg cells in disease pathogenesis and treatment. Front Endocrinol. 2013:4.76. 
43. Butkowski EG, Jelinek HF. Hyperglycaemia, oxidative stress and inflammatory markers. Redox Rep. 2017;22(6):257-64.

44. Plein LM, Rittner HL. Opioids and the immune system-friend or foe. British J Pharmacol. 2018;175(14):2717-25.

45. Hadžiomerović D, Rabenbauer B, Wildt L. Normalization of hyperinsulinemia by chronic opioid receptor blockade in hyperandrogenemic women. Fertil Steril. 2006;86(3):651-7.

46. García-Barrado MaJ, Iglesias-Osma MaC, Rodríguez R, Martín M, Moratinos $J$. Role of $\mu$-opioid receptors in insulin release in the presence of inhibitory and excitatory secretagogues. Eur J Pharmacol. 2002;448(1):95-104.

47. Mendez IA, Ostlund SB, Maidment NT, Murphy NP. Involvement of endogenous enkephalins and $\beta$-endorphin in feeding and diet-induced obesity. Neuropsychopharmacology. 2015;40(9):2103-12.

48. Henriksen G, Willoch F. Imaging of opioid receptors in the central nervous system. Brain. 2008;131(5):1171-96.

49. Paul A, Guven N, Dietis N. Opioid receptor-dependent modulation of insulin-release in pancreatic beta-cells. UK J Pharmaceut Biosci. 2014;2(6):22-31.

50. Tudurí E, Nogueiras R. Mu opioid receptor: from pain to glucose metabolism. Oncotarget. 2017:8(4):5643.

51. Tzeng T-F, Lo C-Y, Cheng J-T, Liu I-M. Activation of $\mu$-opioid receptors improves insulin sensitivity in obese Zucker rats. Life Sci. 2007;80(16):1508-16.
52. Tzeng T-F, Liu I-M, Cheng J-T. Activation of opioid $\mu$-receptors by loperamide to improve interleukin-6-induced inhibition of insulin signals in myoblast C 2 C 12 cells. Diabetologia. 2005;48(7):1386-92.

53. Zhou X, Wang D, Zhang Y, Zhang J, Xiang D, Wang H. Activation of K-opioid receptor by U50,488H improves vascular dysfunction in streptozotocin-induced diabetic rats. BMC Endoc Dis. 2015;15(1):1-11.

54. Satta M, Maussier M, Scoppola A, Menini E, Liberale I, Lio S, et al. Endogenous opiate modulators of insulin secretion in the obese. C R Seances Soc Biol Fil. 1988;182(6):538-43.

55. Ritter M, Sönnichsen A, Möhrle W, Richter W, Schwandt P. Beta-endorphin plasma levels and their dependence on gender during an enteral glucose load in lean subjects as well as in obese patients before and after weight reduction. Int J Obes. 1991;15(6):421-7.

56. Hellman B, Grapengiesser E. Glucose-induced inhibition of insulin secretion. Acta Physiol. 2014;210(3):479-88.

\section{Publisher's Note}

Springer Nature remains neutral with regard to jurisdictional claims in published maps and institutional affiliations.
Ready to submit your research? Choose BMC and benefit from:

- fast, convenient online submission

- thorough peer review by experienced researchers in your field

- rapid publication on acceptance

- support for research data, including large and complex data types

- gold Open Access which fosters wider collaboration and increased citations

- maximum visibility for your research: over $100 \mathrm{M}$ website views per year

At BMC, research is always in progress.

Learn more biomedcentral.com/submissions 